\title{
Polyphenols more than an Antioxidant: Role and Scope
}

\author{
Syed Khalid Mustafa ${ }^{*}(\mathbb{D})$, Atif Abdul Wahab A. Oyouni ${ }^{2}$ (D), \\ Meshari M.H. Aljohani ${ }^{1}$ (D) and M. Ayaz Ahmad ${ }^{3}$ (D) \\ ${ }^{1}$ Department of Chemistry, ${ }^{2}$ Department of Biology, ${ }^{3}$ Department of Physics, Faculty of Sciences, University of \\ Tabuk, Kingdom of Saudi Arabia.
}

\begin{abstract}
In this article, an attempt has been made review on phenolics antioxidant activity, and characteristics, as well as the constituents of the different phenolics present in various consumable food items, which reduce the risk of non-communicable diseases. Some polyphenolic compounds are present in selected species, which are beneficial to public health, and it should be comprised as component of food habits for a proper nutrition's plan. Polyphenols are basically a natural compound and their micronutrients are found in different fruits, beverages, and vegetables. There is no specific deficiency disease caused due to the low dietary intake of phenolics; while the proper intake possibly gives health benefits. Polyphenols are antioxidants, and evidence for their role with improved heart health, neurodegenerative (Alzheimer's disease) diseases, better blood sugar control, diabetes, reduced inflammation, and a reduced risk of cancer development was studied. A comprehensive understanding of the biological availability of the nutritional polyphenols will helpful to recognize those that are beneficial and protective for human health. Based on latest reports, polyphenolic compounds occupy a unique place in environmental science as an important and common class of bioactive natural products globally. It is building a bridge between different interdisciplinary academic fields of science. This work is based on the reports examined the health effect of polyphenols until today.

Keywords: Phytochemicals, antioxidants, polyphenols, Food sources, Dietary intake, Non-Communicable Diseases, Bioavailability
\end{abstract}

\footnotetext{
*Correspondence: khalid.mustafa@gmail.com; +966531210675
}

(Received: October 03, 2019; accepted: February 10, 2020)

Citation: Syed Khalid Mustafa, Atif Abdul Wahab A. Oyouni, Meshari M. H. Aljohani and M. Ayaz Ahmad, Polyphenols more than an Antioxidant: Role and Scope, J. Pure Appl. Microbiol., 2020; 14(1): 47-61. https://doi.org/10.22207/JPAM.14.1.08

(C) The Author(s) 2020. Open Access. This article is distributed under the terms of the Creative Commons Attribution 4.0 International License which permits unrestricted use, sharing, distribution, and reproduction in any medium, provided you give appropriate credit to the original author(s) and the source, provide a link to the Creative Commons license, and indicate if changes were made. 


\section{INTRODUCTION}

As per present (WHO) World Health Organization's 2019 reports, the world is facing multiple health challenges. Non-Communicable diseases (NCDs), interpreted as diseases that cannot be transmitted from one individual to another, such as heart diseases, most cancers, type 2 diabetes, chronic kidney disease, osteoarthritis, Parkinson's disease, autoimmune diseases (like arthritis), strokes, osteoporosis, Alzheimer's disease, are as a whole cause for over $70 \%$ of gross deaths worldwide, or 41 million individuals yearly ${ }^{1}$. According to another report posted in The Lancet (3 April 2019), anticipated 11 million deaths per year (one in all five deaths) are only due to poor diet eating ${ }^{2}$. Workers consider that improvements in the quality of dietary intake could potentially avoid one in every five deaths internationally. Consuming an unhealthful diet increases the possibility of a number of chronic diseases; malnutrition is cause for additional deaths than any other factors leading. Therefore, NCDs are now regarded as a key health problem in developing as well as developed nation's people. In favor of public health concern, WHO recommended increasing the use of fruits and vegetables, essential vitamins and minerals, fiber, and phytochemicals that can give health benefits, and may well help to decrease the menace of $\mathrm{NCDs}^{3-7}$.
In January 2019, The Lancet released the EAT-Lancet commission; a report based on 2016 figures from the worldwide burden of disease survey to assess how far-off the world is from the proper nutrition's planned and suggested the first scientific targets for a healthy human $\operatorname{diet}^{8}$. Meanwhile, many workers and food manufacturers have taken curiosity in polyphenols, as their greatest abundance of our dietary sources, antioxidant behavior, and their credible function in the prevention of different diseases related to the oxidative stress, like cancer, cardiovascular, and neurodegenerative diseases.

Phenol has a hydroxyl group joined to an aromatic benzenoid-ring. Polyphenols are nothing but Polyhydroxy phenol. The term polyphenol has been in practice since $1894^{\circ}$. The wealthiest polyphenols are the concentrated tannins, present approximately in all classes of plant's life and are densely in tissues of leaf, the epidermis, bark layers, flowers, and fruits etc. One can see the structure of tannic acid in Fig. 1.

Tannins is a yellowish or brownish colored substance present in some galls, barks, and the other plant's tissues made up of derivatives of Gallic acid (3,4,5-trihydroxy benzoic acid). A large number of organic, synthetic or semi-synthetic polyphenolic compounds are known from the simple compound Gallic acid,(as shown in Fig.<smiles>O=C(OC[C@H]1OC(OC(=O)c2cc(O)c(O)c(OC(=O)c3cc(O)c(O)c(O)c3)c2)[C@@H](OC(=O)c2cc(O)c(O)c(OC(=O)c3cc(O)c(O)c(O)c3)c2)C(OC(=O)c2cc(O)c(O)c(OC(=O)c3cc(O)c(O)c(O)c3)c2)[C@H]1OC(=O)c1cc(O)c(O)c(O)c1)c1cc(O)c(O)c(OC(=O)c2cc(O)c(O)c(O)c2)c1</smiles>

Fig.1.The structure of tannic acid 
2) to complex compound Raspberry ellagitannin(as depicted in Fig. 3).

Raspberries contain a high level of ellagitannin. It is a complex polyphenol, having 6 ellagic acid-model type elements, in addition to two monomeric phenolic, so 14 Gallic acid units are in aggregate. These polyphenolic compounds have a distinctive physical, chemical, and biological property (i.e., metabolic, toxic, therapeutic, etc.).

A number of compounds of phenolic structures have been discussed and characterized by many workers from time to time; because polyphenol groups (i.e. several hydroxyl radicals on aromatic rings) compounds are found abundantly in naturally occurring plant kingdom. In general, polyphenols are present in nature in the conjugated structure with one or over sugar residues linked with a hydroxyl group of phenol, while the direct association of the sugar part to an aromatic carbon atom can take place as well ${ }^{10-16}$.

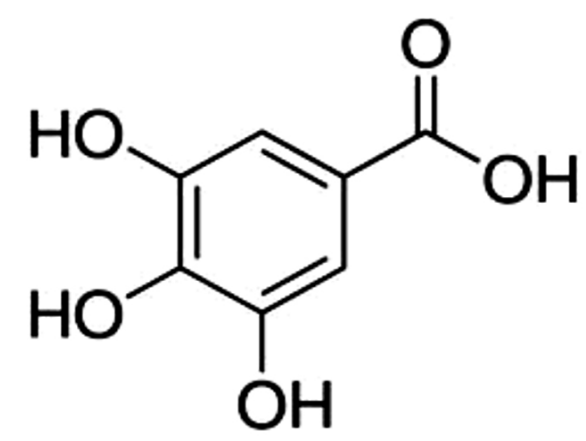

Fig. 2.The structure of the Gallic acid $(3,4$, 5-trihydroxybenzoic acid).
The biological properties of polyphenols comprise anticancer, antioxidant, and antiinflammatory impacts. Polyphenols have antimicrobial and anti-cariogenic properties and are an important source as anti-infective elements towards against antibiotic-resistant human pathogens. As antioxidants, polyphenols are the most abundant a Man daily diet. In the last few years, a sufficient volume of researches evaluating the physiological behavior of dietary-derived bioactive and dietary ingredients with functional properties have noticeably raised. Foodstuffs having bioactive compositions are reducing the risks of many chronic diseases that are getting the key sources of worldwide morbidity and mortality rates $^{17,18}$.

\section{Classification of Various Polyphenols}

Polyphenols can be categorized as according to the phenol rings exist and the structural parts that unite these rings collectively, characterizing the molecules as phenolic acids, flavonoids, stilbenes, and lignans, as shown in [Fig. 4-7]. Polyphenols may be combined with different carbohydrates and organic acids together.

\section{Phenolic acids}

They are non-flavonoid polyphenolic compounds, subdivided into two key groups, derivatives of benzoic acid and cinnamic acid; depend on the arrangement of C1-C6 and C3-C6 as shown in Fig. 4.

Flavonoids

They have a simple structure with two benzenoid rings ( $A$ and $B$ ) that are bonded mutually by 3 carbon atoms that make an oxygenated

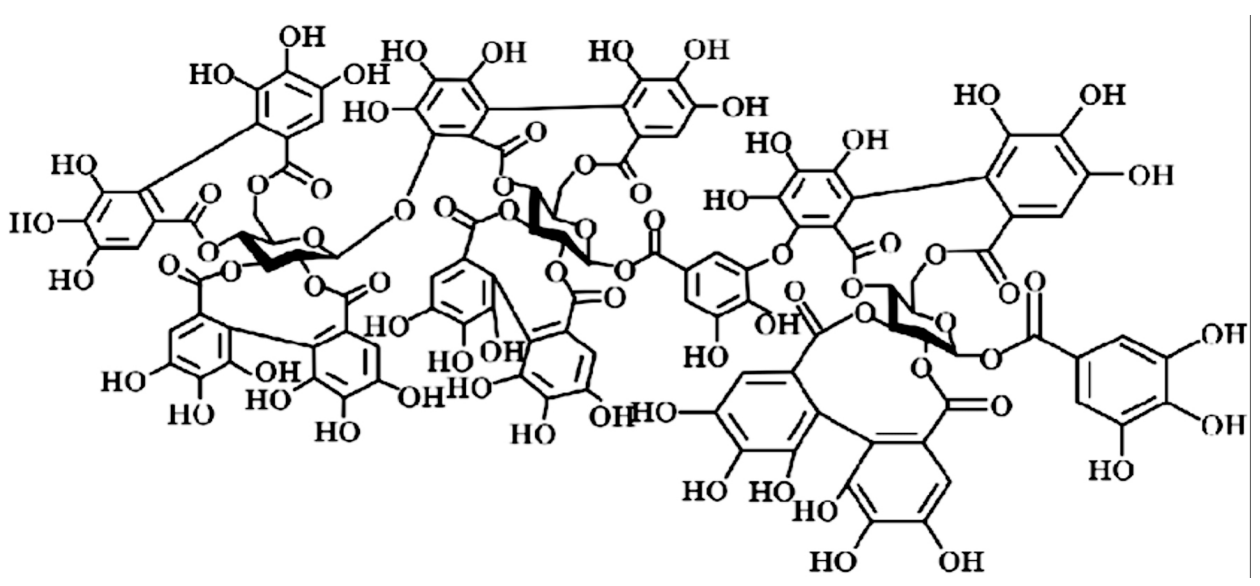

Fig. 3. A chemical structure of ellagitannin 

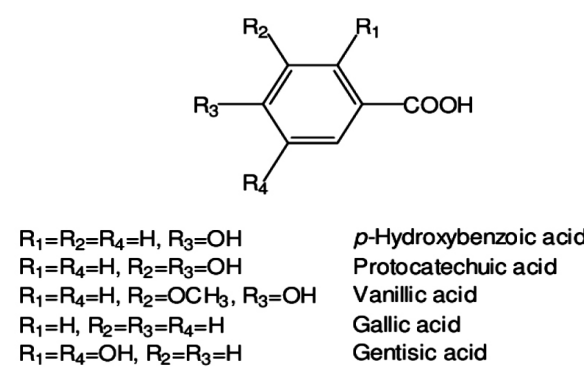

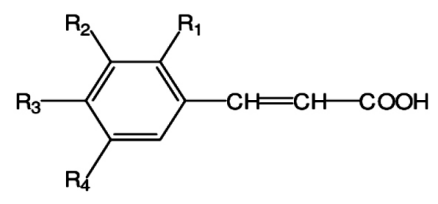

$\mathrm{R}_{1}=\mathrm{R}_{2}=\mathrm{R}_{4}=\mathrm{H}, \mathrm{R}_{3}=\mathrm{OH}$

p-Coumaric acid

$\mathrm{R}_{1}=\mathrm{R}_{4}=\mathrm{H}, \mathrm{R}_{2}=\mathrm{R}_{3}=\mathrm{OH} \quad$ Caffeic acid

$\mathrm{R}_{1}=\mathrm{R}_{4}=\mathrm{H}, \mathrm{R}_{2}=\mathrm{OCH}_{3}, \mathrm{R}_{3}=\mathrm{OH} \quad$ Ferulic acid

Fig. 4. The structure of phenolic acids

heterocyclic (ring C), further subdivided as flavonols, flavones, isoflavones, flavanones, anthocyanidins, and flavanols (catechins and proanthocyanidins). Flavonoids and phenolic acids are the most common classes.

Flavonoids or bioflavonoids are classified as plant and fungi secondary metabolites. Flavonoids have the common arrangements with a 15-carbon atoms which contains two benzene rings ( $A$ and $B$ ) and a heterocyclic ring $(C)$, depicted in Fig. 5.

Stilbene

1, 2-diphenylethene structural formula $\mathrm{C}_{6} \mathrm{H}_{5} \mathrm{CH}=\mathrm{CHC}_{6} \mathrm{H}_{5}$ \} exist in the cis and trans form. Classified as a diarylethene, it has a central ethylene group attached with one phenyl group substituents on each end of the carbon-carbon double bond (Fig. 6).

Lignans

The lignans are a large collection of polyphenols present in plant life. Flaxseed and sesame are the best sources of lignans than most other foods. Fundamentally the chemical structures of lignans have two phenyl propane groups attached to a $\mathrm{C}-\mathrm{C}$ bond connecting the central atoms of the particular side chains (position 8 or $\beta$ ), also named $\beta-\beta^{\prime}$ bond, as it has been illustrated in Fig. $7^{14-15,18}$.

Leading Food sources with Polyphenols

More than 8,000 types of polyphenols have been identified. Polyphenols are found in high amount mainly, in coffee, berries, and dark chocolate, cocoa powder, olive oil, in certain spices and seasonings, like cloves and star anise. Some of the top sources of polyphenol foods that should be added in daily diet intake have been shown in Table 1.

\section{Olive Oil}

The least processed form of olive oil is called Extra-virgin olive oil; it has the dense collection of polyphenolic compounds, extracted from the olive fruit. Consuming of olive oil as a diet inappropriate quantity

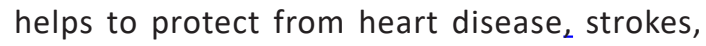
metabolic syndrome, and some kinds of cancer diseases. ${ }^{19,20}$.

\section{Health Effect of Polyphenols}

There is no doubt that food can act as natural medicine, our diet can determine our destiny and fate. Polyphenols including flavonoids, tannins, lignans, and stilbenes are the most abundant phytochemicals in our diet. Polyphenol-rich foods found in fruits, vegetables, nuts, and seeds are medicine to enhance our health quality and life span. The modes of action of different polyphenolic compounds, more than ever as correlated to reduced menace of disease in individuals, are not entirely explained. A number of show antioxidant behaviors, while others activate defense mechanisms that improve the 


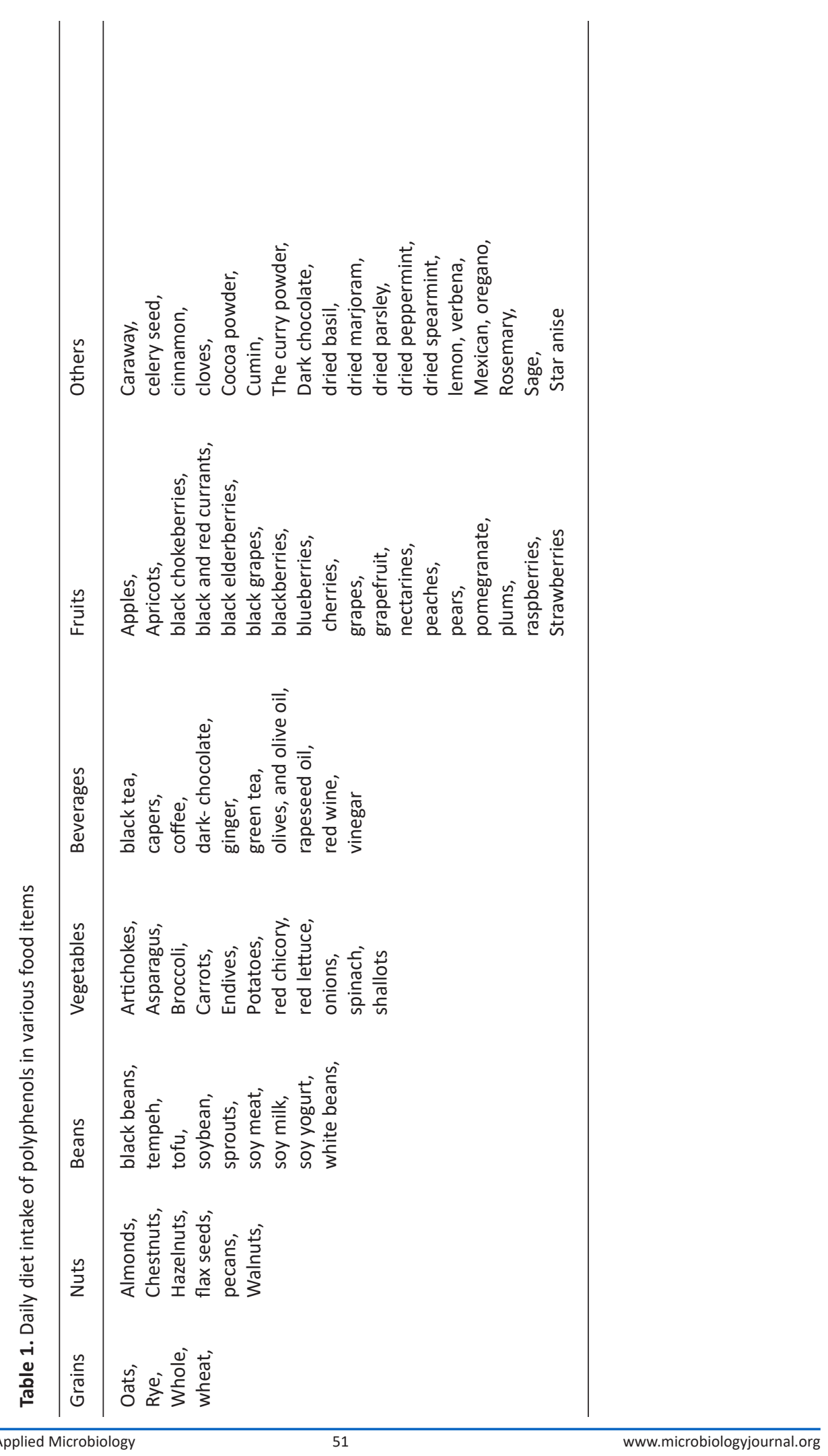


response to oxidative stress and preventing from extensive damage. They have been associated with numerous valuable effects on human being health. Currently, many researchers have taken an interest in polyphenols, because of their antioxidant nature, large quantity in our food, and their action in the prevention of different diseases related to oxidative stress, such as cancer, cardiovascular and neurodegenerative diseases. Intake of polyphenols can be achieved by consuming a large variety of plant foodstuff because the main resource of polyphenols is dietary. This dietary polyphenol includes honey, most legumes and fruits are all rich in polyphenols. Meanwhile, fruits such as apples, pomegranate, strawberries, blackberries, Aronia berries, cranberries, blueberries, raspberries, cherries, cantaloupe, grapes, plums, and pears are all rich in polyphenols. In addition, vegetables such as parsley, broccoli, celery, cabbage, and onion, green tea, white tea, black tea, chocolate, as well as olive oil, are rich in polyphenols ${ }^{16-21}$.

\section{Polyphenols as an Antioxidant}

Compounds that repress oxidation are called antioxidants. Oxidation is a chemical process that is able to generate free radicals. Atom or group of atoms that has an unpaired electron called free radicals. They are generally unstable and very reactive for the reason that unpaired electrons are likely to form pairs with other electrons. When the metabolism taking place in a living organism: an oxygen molecule $\left(\mathrm{O}_{2}\right)$ undergoes four-electron reduction. Reactive

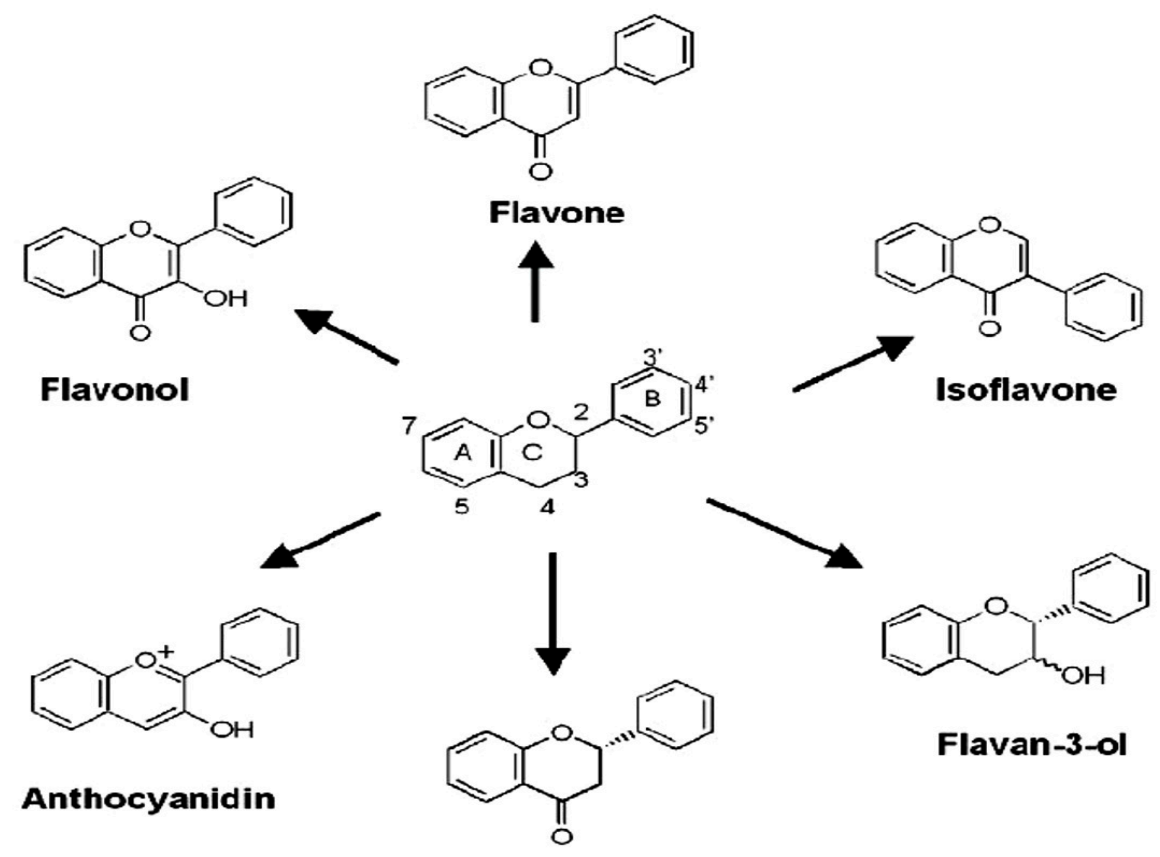

Flavanone

Fig. 5. The structure of flavonoids<smiles>C(=C/c1ccccc1)\c1ccccc1</smiles>

trans-stilben<smiles>C=C=Cc1ccccc1</smiles>

cis-stilben
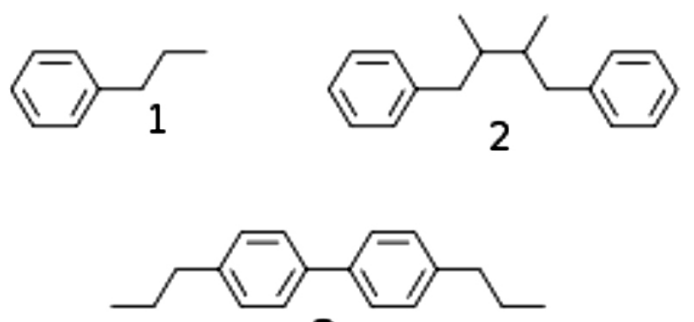

3

Fig. 6. The structure of Stilbene

Fig. 7. The structures of lignans 
oxygen metabolites are generated in this process, maybe due to the excitation of electrons, the addition of energy or interaction with transition elements. These generated reactive oxygen metabolites are extremely reactive than the oxygen molecule, are called active oxygen species. Superoxide $\left(\mathrm{O}_{2}^{-}\right)$, hydrogen peroxide $\left(\mathrm{H}_{2} \mathrm{O}_{2}\right)$, hydroxyl radicals $\left(\mathrm{OH}^{*}\right)$, and singlet oxygen $\left({ }^{1} \mathrm{O}_{2}\right)$ is the example of active oxygen species. In living cells, the formations of free radicals are taking place mainly due to the homolytic chemical bond fission, photolysis, and radiolysis, and due to red-ox reactions. The free radicals are initiating the chain reaction in the living organism, which may lead to cell damage, thus inducing various diseases. Antioxidants are such substances that terminate the chain reaction, initiated by the free radicals in the living organism. In other words, antioxidants neutralize or deactivate the action of reactive oxygen species (free radicals), and protect the living organism from the harmful consequence of the free radicals. The difference between the formation of highly reactive oxygen groups (free radicals) and antioxidant defenses, called Oxidative stress. Produced free radical species attack the existing pro-oxidants (molecules or ions) because it has a very high affinity to combine with others. The human body depends on various endogenous resistance mechanisms to defend against free radical-induced cell injure. Impair of the body cells due to reactive oxygen species (free radicals) plays a significant character in the aging development, and in disease growth or development.

It has been recommended that an insufficient nutritional consumption of a nutrient may be compromised with the efficiency of these antioxidant resistance mechanisms. Many daily practices are directly related to oxidative stress, such as smoking, drinking, irregular diet, and dietary habits. Polyphenol act as an antioxidant, it removes the free radicals and to stimulate certain metal chelation reactions. Singlet oxygen, peroxynitrite, and hydrogen peroxide, as different reactive oxygen species, are required to be constantly removed from cells to keep healthy metabolic function. Several benefits may be associated with ion transport systems by eliminating and decreasing the concentrations of reactive oxygen species (free radicals).

The antioxidant nature of polyphenols
( $\mathrm{PhOH})$ is based on the contribution of an $\mathrm{H}$-atom, which disrupts and terminates the succession reactions initiated by the free radicals in the living organism.

$\mathrm{R} \bullet+\mathrm{PhOH} \rightarrow \mathrm{R}-\mathrm{H}+\mathrm{PhO} \bullet$

The generated phenoxyl radicals ( $\mathrm{PhO} \bullet$ ) maybe stabilized through the resonance or by the self-combination of $(\mathrm{PhO} \bullet)$ to yield dimer products, and finally terminating the chain reaction.

$\mathrm{PhO} \bullet+\mathrm{PhO} \bullet \longrightarrow \mathrm{PhO}-\mathrm{OPh}$

More than 8,000 types of natural polyphenols have been identified. Meanwhile, polyphenols are made up of multiple phenol units and are found naturally in many dietary sources, associated with many health benefits due to their antioxidant content ${ }^{21-28}$.

\section{Anticancer effects and Polyphenols}

Cancer treatment and cancer prevention is a big challenge for the whole scientific community. According to WHO January 2019 reports cancer is the next most important reason of death internationally and is likely to account for 9.6 million deaths in 2018. In other words, approximately one in six deaths due to cancer reported internationally. About $30-50 \%$ of all cancer cases are possibly preventable. A balanced diet, to get the proper nutrition is a better strategy in prevention more than in cancer therapy. Dietary adaptation and alteration are an important approach to cancer control. Consumption of fruits and vegetables may have an impressive defensive outcome against several cancers such as the oesophagus, colorectal, breast, endometrium, and kidney. Healthy eating is a way of life that helps to check the development of diet-related cancers will also decreases the probability of other noncommunicable diseases [NCDs] $]^{29}$.

A number of studies from different workers have documented the anti-carcinogenic features of natural polyphenols. Natural polyphenols have anticancer effects mainly due to their powerful antioxidant and anti-inflammatory actions, additionally their effectiveness to modulate molecular targets and signaling pathways, which were affiliated with cell life, migration, separation, proliferation, immune responses, detoxification enzymes, angiogenesis, hormone activities, etc. ${ }^{30-35}$.Including, anthocyanins, delphinidin has strong anticancer activities; it 
follows the mechanism of induced apoptosis and cell cycle arrest in different classes of cancer. Peonidin-3-glucoside and cyanidin-3glucoside induce apoptosis and selectively reduced cell proliferation and abnormal development with HER2 positive breast cancer, and also repressed lung cancer cells growth by down-regulating the matrix metalloproteinase (MMP) expression ${ }^{36-39}$. Cyanidin-3-O-sambubioside has a preventive effect and also suppresses the development of breast cancer cells ${ }^{40}$.

Researchers proclaimed that nonacylated monoglycosylated anthocyanins were well effective in suppressing the uncontrolled growth of cancer cell, as compared to anthocyanins with pelargonidin aglycone and tri glycosylation ${ }^{41}$. Many polyphenolic compounds, like quercetin, catechins, isoflavones, lignans, flavanones, ellagic acid, anthocyanidins, xanthohumol, resveratrol, or curcumin showed protective and suppressive effects by different mechanisms in some cancerous model's studies ${ }^{42}$. Epigallocatechin gallate (EGCG), also recognized as epigallocatechin-3-gallate, is an ester of epigallocatechin and gallic acid, a kind of catechin, and components of green tea, which reduces the risk of various cancers like those of the bladder, prostate, esophagus, and stomach $^{43}$.Curcumin (diferuloylmethane) has antitumor potentials (which suppress the cellular proliferation and angiogenesis), prevents of tumor cell cycle progression, anti-kinase activity and inducing programmed cell death in vitro and in vivo. It also controls NF-KB activation AP-1 DNA binding, signal transducer and also activatesthetranscription-3 (STAT 3) phosphorylation in vitro ${ }^{44}$. Flavonoids of astragalus mongholicus have much biological activity such as anti-injury and anti-mutation properties, and also have an important suppression outcome on the human being hepatocellular carcinoma BEL7402 cells and induce the cell cycle retardation in the G0/G1 phase, particularly in the $G 1$ phase. Cyclind1 starts to express between the $\mathrm{G} 0$ and the $\mathrm{G} 1$ phases and takes part in the regulation of the $\mathrm{G} 1$ phase due to the association of cyclindependent kinases 4 (CDK4) and 6 (CDK6), conducting to the progression of the cells into the $S$ phase (replication of DNA). An uncontrollable expression of cyclind1 deregulation of the cell cycle will be resulting from CDK4/CDK6. Flavonoids decrease the expression of cyclind1, which is most possible due to the inhibiting property of these compounds in the propagation of $\mathrm{K} 562$ and maintaining additional cells in the G0/G1 phase ${ }^{45}$.

\section{Cardiovascular Diseases and Polyphenols}

According to the World Health Organization (WHO) -Reports, Cardiovascular diseases (CVDs) are the key reason of death internationally. Approximately 17.9 million public died from CVDs in 2016; mean $31 \%$ of all total deaths number. About $85 \%$ of the above mentioned death's figure is because of heart attack and stroke. About 75 percent of the world's deaths from CVDs happen in low- and middle-income countries ${ }^{46}$. Heart Disease and Stroke Statistics - 2019 keep up to date from the American Heart Association mentions that: 116.4 million or $46 \%$ of US people age of above 18 are likely to have hypertension (high blood pressure). According to the published data of (WHO) 2016, about 2303 deaths were reported every day from $\mathrm{CVD}^{47}$. Cardiovascular diseases (CVDs) are a kind of diseases in which heart or blood vessels are involved.

Polyphenols from different sources of food like cocoa, coffee, tea, and apples have been related with a number of healthassociated benefits, as well as cardiovascular disease ${ }^{6-7,48-52}$. Epidemiological studies recommend that consumption of polyphenols because it is clearly associated with the reduction in the CVD prevalence ${ }^{53-54}$. Currently, researchers suggested that owing to antithrombotic, anti-inflammatory, and anti-aggregative character of Polyphenolic compounds; they are acting at the molecular level, improving endothelial function, and reducing platelet aggregation as well. Thus, in the prevention and treatment of cardiovascular disease, polyphenolic compounds play important roles. It is suggested that people with a better consumption of flavonoids in their diets have a $47 \%$ lower occurrence of cardiovascular incidence against to those with the lowest consumption ${ }^{55}$. It was suggested that the consumption of flavan-3ol from different nutritional sources are beneficial for cardiometabolic consequences, also decreasing the menace of diabetes, and cardiovascularassociated results (i.e. cholesterol levels, blood pressure, and myocardial infarction). Several foods like tea; nuts, cocoa (chocolate), grapes, and 
legumes consuming regularly have a high content of flavan-3-ols, a commonly known polyphenol ${ }^{56-61}$. Rich source of anthocyanins, a kind of flavonoids, are red and blue fruits and vegetables, especially blueberries, raspberries, strawberries, bilberries, red grapes, and cherries, etc. A dietary intake of anthocyanins, similar to other polyphenols, are metabolized by the host and the micro biome to shape active metabolite that has anti-inflammatory characteristics and produce positive vascular outcome, and also decrease the threat of myocardial infarction in men and women and cause additional favorable effects on cardiovascular risk factors ${ }^{62-64}$. Resveratrol is a Stilbene and is largely occurs in grapes, red wine, and berries have anti-inflammatory and antioxidant actions, and also activates the sirtuins, which produce a positive effect on aging. It is reported, that supplementation of resveratrol appreciably controls fasting glucose, total cholesterol, C-reactive protein (CRP), and systolic and diastolic blood pressure. Quercetin, a flavonol found in the apple that has been appeared to enhance the endothelial function, reduces systolic blood pressure, and decreases the menace of cardiovascular disease $\mathrm{s5}^{65}$.

\section{Diabetes and Polyphenols}

Diabetes is one of the most major community health problems in the world and according to WHO estimates that diabetes was the 7 th leading cause of death in 201670-71. A healthy diet can facilitate to prevent the development of diabetes and can retard the complication of diabetes. Polyphenols -rich diets have the potential to defend against type 2- diabetes (formerly called non-insulin-dependent, or adult-onset). Polyphenolic compounds stimulate the secretion of insulin, a hormone that is needed to shuttle sugar from the bloodstream into the cells and keeping the blood sugar levels normal. It may also prevent the breakdown of starch into simple sugars, and keeping the blood sugar level stable after meals. Various studies suggested that polyphenolrich diets may help in, to lower the fasting blood sugar levels, higher glucose, tolerance, and increasing insulin sensitivity - all these factors are protecting from type 2 diabetes72-73. It is also suggested that people taking the highest amounts of polyphenol-rich diets had up to a $57 \%$ reduce menace of developing type 2 diabetes over 2-4 years, compared with those taking the lowest amounts. Among polyphenolic compounds, anthocyanins and procyanidins have the most potent anti-diabetic effect, which is found in red, purple, and blue foods, such as berries, currants, and grapes, bark, leaves, popular drinks like cocoa, coffee, green tea and seeds of many plants and plant-derived food ${ }^{74-75}$.

\section{Alzheimer's disease and Polyphenols}

Alzheimer's disease (AD) is another major widespread neurodegenerative disorders, which is due to the damage of nerve structure and function and eventually leading to the death of nerve cells in the human brain, affecting older people worldwide $\mathrm{f}^{76-77}$. According to the recently revealed facts from the World Health Organization (WHO)-Worldwide, about 50 million inhabitants are suffering from Alzheimer's disease or other dementias, and the number will be exceeded 152 million by the year 2050 About 60 percent of people living with dementia worldwide are from a low- or middle-income country ${ }^{78}$.

Genetic and environmental aspects are considered as a risk concern in Alzheimer's disease $(A D)^{79-80}$. Free radicals are highly reactive chemical groups having an odd number of electrons and are formed in course of the both physiological and pathological processes. While reactive oxygen species (ROS) take part in a number of cellular and signaling pathways at physiological concentrations (cell cycle regulation, phagocytosis, and enzyme activation), an undue production of ROS have various unhealthy effects together with DNA, lipid, and protein damage ${ }^{81-84}$. An inequality in the status of oxidant-antioxidant could lead to cell damage. Oxidative impair as a outcome of ROS has been suggested in the pathogenesis [the development, mechanism, and progress of disease] of neurodegenerative diseases, cancer, diabetes, and aging ${ }^{85}$.

Comprehensive academic works reported that the superoxide anion; the hydroxyl radical, hydrogen peroxide, and nitric oxide play a vital character in the in oxidative stress eventually leading to neurodegenerative disease Alzheimer ${ }^{86-87}$. ROS is, however, removed by the defense mechanisms, called as enzymatic and non-enzymatic antioxidants. Polyphenolic compounds have antioxidant character and take part in a foremost neuroprotective role. It 
is recommended that dietary supplementation of dates, pomegranate juice, and figs (rich in polyphenols) improved intellectual disability and behavioral discrepancy by keeping oxidantantioxidant equilibrium in APPsw/Tg 2576 transgenic species. Workers also reported that walnut (Walnut polyphenols have the best efficacy among the nuts) extract has a strong potential to prevent amyloid-beta peptide-induced oxidative stress in PC12 cells ${ }^{88-90}$.

\section{Anti-Cariogenic Properties of Polyphenols}

Dental caries (tooth decay) are one of the most widespread and major oral health problems of the world, have an impact on 60$90 \%$ of children and the mass of adults ${ }^{91}$.Oral flora, teeth, and dietary factors play a role in dental caries disease. Dietary carbohydrates ((sucrose or sugars) are occupied into dental plaque and broken down into organic acids (lactic acid) by bacteria (exist in dental plaque on the outer surface of tooth). In due course, formed acid is responsible for the loss of calcium and phosphate from the tooth's surface, called demineralization (meaning that there is a net loss of mineral structure on the tooth's surface). The antibacterial role of polyphenols, found in tea, coffee, red grape seeds, and cocoa can also play a role in the keeping off from cariogenic processes: they may decrease the rate of growth of bacteria and keeping the tooth surface protected, and also can have inhibitory effects on the enzymatic activity of glucosyltransferase and amylase. Flavonoids seem to be a favorable anti-cariogenic molecule ${ }^{92-95}$.Anti cariogenic effects of phenolic compounds can be separated into two groups:(I) Plant extracts having high concentrations of polyphenols, without the recognition of particular compounds present in the extracts and (II) Antibacterial activity of specific polyphenolic compounds. The extracts from unfermented cocoa, green tea, and red grape seeds, all with a high polyphenols content is effective against $\mathrm{S}$. mutants and periodontal diseases ${ }^{96-97}$.Quercetin3-O- $\alpha$-L-arabinose-pyranoside (guaijaverin), an active flavonoid compound has high probable anti plaque outcome by inhibiting the development of S. mutants ${ }^{98}$.

Magnolol and honokiol isolated from extracts of Magnolia sp. bark having a phenylpropanoid dimer structure, known flavonoids, isoflavonoids, dihydrobiochanin A, ferritin, and darlbergioidin, and also is oflavonoid, 5, 2', 4' -trihydroxy-7-methoxy isoflavone (dihydro cajanin), extracted from Swartzia Polyphylla DC heartwood have strong activity against cariogenic bacteria ${ }^{99-100}$. A lavandulyl flavone extracted from Sophora Exigua Craig absolutely inhibited the oral bacterial growth, as well as primary cariogenic mutans streptococci, other oral streptococci, actinomycetes, and lactobacilli ${ }^{101}$.Isoprenyl flavones isolated from Artocarpus heterophyllus and erycristagallin isolated from Erythrina variegate exhibited antibacterial action against cariogenic bacteria ${ }^{102-103}$.

In the last few years, polyphenols extracted from Perillafrutescens var. japonica seeds have suppressive action against oral cariogenic Streptococci and periodontopathic Porphyromonas gingivalis. Polyphenols isolated from Perilla seed and flavonoid luteolin have active inhibiting property against bacterial growth ${ }^{104-105}$. The regular intake of black tea (theaflavins antioxidant polyphenols) considerably decreased caries development by $56.6 \%$ in the hamster on a standard diet and by $63.7 \%$ in hamsters on a cariogenic diet ${ }^{106}$.

\section{Antimicrobial activity of Polyphenolic Compounds}

Polyphenolic compounds show significant antibacterial activity as well. These days' people are using several plant extracts, rich in phenolic compounds as natural food and cosmetic preservatives in alternatives to a synthetic one. Phenolic compounds found in the fruits may well be used as a potential natural antibacterial agent. The tropical fruits like guava, persimmon, and sweetsop, have an antioxidant and antibacterial activity that supported the possibility of developing the fruits into a novel natural resource and functional food in addition to the new natural antimicrobial agents and food preservatives. Probably, the phenolic compound's effects were well heterogeneous ranging from bacterial growth stimulation to antibacterial activity and depended on bacterial strains. Antibacterial action mechanisms of the phenolic compounds are not so far completely explained but these compounds are recognized to involve several sites of action at the cellular level ${ }^{107-109}$.

Many workers explained antibacterial 
action by the alteration in the permeability of cell membranes, the changes in different intracellular functions induced by hydrogen bonding of the phenolic compounds to enzymes or by the change of the cell wall rigidity along with integrity losses because of different interactions with the cell membrane. Therefore, the elevation of the lipophilic nature of phenolic compounds enhances their antimicrobial activity by favoring their interaction with the cell membrane ${ }^{109-113}$.

\section{DISCUSSION}

Recently, the 13th World Congress on the Application of Polyphenols: Malta Polyphenols 2019, (International Society of Antioxidants in Nutrition and Health (ISANH) and the International Society of Microbiota) was concluded on October 1, 2019 at Malta. They made a long discussion on various approaches in product development, exploitation of novel sources of phenolic compounds, characterization, and the application of novel nutraceuticals based on plant phenolic compounds and also new processes for extraction and formulation of polyphenols on a wide scale. They also emphasized on the novel approaches for the scientific developments with regards to polyphenols. Further, the industrialists and scientific communities mulled together to explore the promising future of polyphenols, to meet the common goal of serving humanity at large.

Finally, based on the present study and analysis, one can say that, it needs a comprehensive investigation into the interrelationship between the bioavailability, metabolism, and bioactivity, including the prevention of neurodegenerative diseases, Non-Communicable diseases (NCDs), such as most cancers, type 2 diabetes, and cardio metabolic effects.

\section{CONCLUSION}

A poor dietary practice has contributed a big percentage in the growth of chronic diseases, as well as diabetes, hypertension, cancer, and cardiovascular diseases. The phophenolic compounds have been related with numerous advantageous consequences on individual health. Detailed awareness of the bioavailability of the nutritional polyphenols will facilitate us to classify those that are beneficial and protective for public health effects. Therefore, the nutritionists have a task to educate communities on the health benefits of phytochemicals. People should also need to know foods rich in these phytochemicals and preparation methods of enhancing the bioavailability of different phytochemicals. Foodstuff rich in polyphenols for instance fruits, vegetables, nuts, and seeds act as a natural medicine to enhance our health quality and life span. There is no doubt that our food habits can determine our destiny and fate. A very common proverb is used "Prevention is better than cure".

\section{ACKNOWLEDGEMENTS}

The authors would like to acknowledge the keen support for this work of the Department of Chemistry, Faculty of Science, and University of Tabuk, Saudi Arabia.

\section{CONFLICT OF INTEREST}

The authors declare that there is no conflict of interest.

\section{FUNDING}

None.

\section{AUTHORS' CONTRIBUTION}

All authors listed have made a substantial, direct and intellectual contribution to the work, and approved it for publication.

\section{DATA AVAILABILITY}

All datasets generated or analyzed during this study are included in the manuscript.

\section{ETHICS STATEMENT}

Not applicable.

\section{REFERENCES}

1. https://www.who.int/news-room/feature-stories/ ten-threats-to-global-health-in-2019.

2. The Lancet, PUBLIC RELEASE: 3-APR-2019

3. Guidelines: World Health Organization; 2018 (Draft issued for public consultation in May 2018).

4. Referance From the annual compilation departments -The World Health Statistics series, WHO-2018.

5. LG Saldanha. Summary of comments received in response to the Federal Register notice defining bioactive food components, Summary20of20comments20-20 on 20 defining 20 bioactive 20 food 20 components. PDF, accessed November 9, 2017.

6. PC Hollman, A Geelen and D Kromhout. Dietary 
flavonol intake may lower stroke risk in men and women, J. Nutr., 2010; 140: 600-604. https://doi. org/10.3945/jn.109.116632

7 L Hooper, PA Kroon, EB Rimm, JS Cohn, I Harvey, KA Le Cornu, JJ Ryder, WL Hall and A Cassidy. Flavonoids, flavonoid-rich foods, and cardiovascular risk: a metaanalysis of randomized controlled trials, Am. J. Clin. Nutr., 2008; 88: 38-50. https://doi.org/10.1093/ ajcn/88.1.38

8. Published Proceedings by MDPI on the $23^{\text {rd }}$ International Conference on Miniaturized Systems for Chemistry and Life Sciences, ( $\mu$ TAS 2019), during the period of October, 27-31, 2019 at the Congress Center Basel, SWITZERLAND, www.congress.ch

9. Bate-Smith EC. Polyphenol on www.merriam-webster. com online dictionary, 1954.

10. Haslam E and Cai Y. Plant polyphenols (vegetable tannins): Gallic acid metabolism, 1994. https://doi. org/10.1039/np9941100041

11. Edwin Haslam. Practical Polyphenolics: From Structure to Molecular Recognition and Physiological Action. Cambridge University Press, New York, NY. 1998.J. Nat. Prod., 61(11): 1454-1455. https://doi.org/10.1021/ np980243t

12. Quideau et al. Plant Polyphenols: Chemical Properties, Biological Activities, and Synthesis. 2011; 50(3): 586621. https://doi.org/10.1002/anie.201000044

13 Nutrients, 2010 Dec; 2(12): 1231-1246. Published online. https://doi.org/10.3390/nu2121231

14. R Tsao. Chemistry and Biochemistry of Dietary polyphenols, Nutrients, 2010; 2(12): 1231-46. https:// doi.org/10.3390/nu2121231

15. V Cheyneir. Polyphenols in food are more complex than often thought, American Journal of Clinical Nutrition, 2005; 81(1 Suppl): 223S-229S. https://doi. org/10.1093/ajcn/81.1.223S

16. L Bravo. Polyphenols: Chemistry, Dietary Sources, Metabolism, and Nutritional Significance: Nutrition Reviews, 1998; 56(11): 317-333. https://doi. org/10.1111/j.1753-4887.1998.tb01670.x

17. Annuzzi et al. Phenolic metabolites as compliance biomarker for polyphenol intake in a randomized controlled human intervention Food Research International, 2014; 63, Part B: 233-238. https://doi. org/10.1016/j.foodres.2014.01.018

18. Blanca Hernandez-Ledesma et al. Food Bioactive Compounds against Diseases of the $21^{\text {st }}$ Century 2016, BioMed Research International, 2017; 2 pages, Volume. https://doi.org/10.1155/2017/1750823

19. Manach et al. Polyphenols: food sources and bioavailability, The American Journal of Clinical Nutrition, 2004; 79(5): 727-747. https://doi. org/10.1093/ajcn/79.5.727

20 DG Monika et al. Potential Health Benefits of Olive Oil and Plant Polyphenols. Int J Mol Sci., 2018; 19(3): 686. Published online 2018; doi: 10.3390/ijms19030686

21. Halliwell B: Oxidative stress, nutrition and health: Experimental strategies for optimization of nutritional antioxidant intakes in humans. Free Radic. Biol. Med., 1996, 25: 57-74. https://doi. org/10.3109/10715769609145656

22. Halliwell B. Free radicals, antioxidants and human disease: Curiosity, cause or consequence. Lancet, 1994; 344: 721-724. https://doi.org/10.1016/S01406736(94)92211-X

23. Sies $\mathrm{H}(\mathrm{ed})$ : Oxidative Stress II: Oxidants and Antioxidants. New York, NY, Academic, 1991.

24. Birben E, Sahiner UM, Sackesen C, Erzurum S and Kalayci, O. Oxidative stress and antioxidant defense. World Allergy organization; 2012; 5(1): 9-19.

25. Bors W, Heller W, Michel C and Saran M. Flavonoids as antioxidants: Determination of radical Scavenging efficiencies. Methods in Enzymology, 1990; 186: 343355. https://doi.org/10.1016/0076-6879(90)86128-I

26. Rizzo AM, Berselli P, Zava S, Montorfano G, Negroni M, et al. Endogenous antioxidants and radical scavengers. AdvExp Med Biol, 2010; 698: 52- 67. https://doi. org/10.1007/978-1-4419-7347-4_5

27. Williams RJ, Spencer JP and Rice-Evans C. Flavonoids: Antioxidants or signalling molecules? Free Radical Biology and Medicine, 2004; 36(7): 838-49. https:// doi.org/10.1016/j.freeradbiomed.2004.01.001

28. Virgili $\mathrm{F}$ and Marino M. Regulation of cellular signals from nutritional molecules: A specific role for phytochemicals, beyond antioxidant activity. Free Radical Biology and Medicine, 2008; 45(9): 1205-1216. https://doi.org/10.1016/j.freeradbiomed.2004.01.001

29. WHO report on Cancer and guidelines? Available online:https://www.who.int/cancer/en//[2019].

30. Kausar $\mathrm{H}$ and et al. Berry anthocyanidins synergistically suppress growth and invasive potential of human nonsmall-cell lung cancer cells. Cancer Lett., 2012; 325: 54-62. https://doi.org/10.1016/j.canlet.2012.05.029

31. Li AN and et al. Resources and biological activities of Natural Polyphenols. Nutrients, 2014; 6: 6020-6047. https://doi.org/10.3390/nu6126020

32. Shi J and et al. Epigallocatechin-3-gallate inhibits nicotine-induced migration and invasion by the suppression of angiogenesis and epithelialmesenchymal transition in non-small cell lung cancer cells. Oncol.Rep.,2015; 33: 2972-2980. https://doi. org/10.3892/or.2015.3889

33. Rigalli JP and et al. The phytoestrogen genistein enhances multidrug resistance in breast cancer cell lines by translational regulation of $A B C$ transporters. Cancer Lett., 2016; 376: 165-172. https://doi.org/10.1016/j. canlet.2016.03.040

34. Wang $\mathrm{H}$ and et al. Resveratrol inhibits TGF-beta1induced epithelial-to-mesenchymal transition and suppresses lung cancer invasion and metastasis. Toxicology, 2013; 303: 139-146. https://doi. org/10.1016/j.tox.2012.09.017

35. $\mathrm{Li} \mathrm{F}$ and et al. Antiproliferative activities of tea and herbal infusions. Food Funct., 2013; 4: 530-538. https://doi.org/10.1039/c2fo30252g

36. Li F and et al. Antiproliferative activity of peels, pulps and seeds of 61 fruits. J. Funct. Foods, 2013; 5: 12981309. https://doi.org/10.1016/j.jff.2013.04.016

37. Yun JM and et al. Delphinidin, an anthocyanidin in pigmented fruits and vegetables, induces apoptosis and cell cycle arrest in human colon cancer HCT116 cells. Mol. Carcinog., 2009; 48: 260-270. https://doi. org/10.1002/mc.20477

38. Liu W and et al. Selective anti-proliferation of HER2- 
positive breast cancer cells by anthocyanins identified by high-throughput screening. PLOS ONE, 2013; 8: 515. https://doi.org/10.1371/journal.pone.0081586

39. Ho ML \& et al-.Peonidin 3-glucoside inhibits lung cancer metastasis by down regulation of proteinases activities and MAPK pathway. Nutr. Cancer, 2010; 62: 505-516 https://doi.org/10.1080/01635580903441261

40. Lee SJ and et al. Cyanidin-3-O-sambubioside from Acanthopanax sessiliflorus fruit inhibits metastasis by down regulating MMP-9 in breast cancer cells MDA-MB-231. Planta Med., 2013; 79: 1636-1640. https://doi.org/10.1055/s-0033-1350954

41. Jing $\mathrm{P}$ and et al. Structure-function relationships of anthocyanins from various anthocyanin-rich extracts on the inhibition of colon cancer cell growth. $J$. Agric. Food Chem., 2008; 56(20): 9391-8. https://doi. org/10.1021/jf8005917

42. Cragg GM, Newman DJ. Plants as a source of anticancer agents. J Ethnopha-rmacol. Agu, 2005; 100(1- 2): 72-9. https://doi.org/10.1016/j.jep.2005.05.011

43. Scalbert A, Williamson G. Dietary intake and bioavailability of polyphenols. J Nutr., 2000; 130: 207385. https://doi.org/10.1093/jn/130.8.2073S

44. Yang CS, Landau JM, Huang MT, Newmark HL. Inhibition of carcinogenesis by dietary polyphenolic compounds. Annu Rev Nutr., 2001; 21: 381-406. https://doi. org/10.1146/annurev.nutr.21.1.381

45. Zhang D, Zhuang Y, Pan J, Wang H, Li H, Yu Y, et al. Investigation of effects and mechanisms of total flavonoids of astragalus and calycosin on human erythroleuke- mia cells. Oxid Med Cell Longev., 2012; 2012: 209843. https://doi.org/10.1155/2012/209843 46. World Health Organization (WHO Report. https:// www.who.int/news-room/fact-sheets/detail/ cardiovascular-diseases-(CVD), 2017.

47. Heart Disease and Stroke Statistics, Update: A Report from the American Heart Association, 2019.

48. X Liu, X Du, G Han and W Gao. Association between tea consumption and risk of cognitive disorders: $A$ doseresponse meta-analysis of observational studies, Oncotarget, 2017; 8: 43306-43321. https://doi. org/10.18632/oncotarget.17429

49. L Shen, LG Song H Ma, CN Jin, JA Wang and MX Xiang. Tea consumption and risk of stroke: a doseresponse meta-analysis of prospective studies, J. Zhejiang Univ., Sci., 2012b; 13: 652-662. https://doi.org/10.1631/jzus. B1201001

50. K Ried, T Sullivan, P Fakler, OR Frank and NP Stocks. Does chocolate reduce blood pressure? A meta-analysis, BMC Med., 2010; 8: 39. https://doi. org/10.1186/1741-7015-8-39

51. L Hooper, C Kay, A Abdelhamid, PA Kroon, JS Cohn, EB Rimm and A Cassidy. Effects of chocolate, cocoa, and flavan-3-ols on cardiovascular health: a systematic review and meta-analysis of randomized trials, Am. J. Clin. Nutr., 2012; 95: 740-751. https://doi. org/10.3945/ajcn.111.023457

52. MC Serban, A Sahebkar, A Zanchetti, DP Mikhailidis, G Howard, D Antal, F Andrica, A Ahmed, WS Aronow, P Muntner, GY Lip, I Graham, N Wong, J Rysz and M Banach. Effects of quercetin on blood pressure: a systematic review and meta-analysis of randomized controlled trials, J. Am. Heart Assoc., 2016; 5(7): pii: e002713. https://doi.org/10.1161/JAHA.115.002713

53. H Huang, $G$ Chen, $D$ Liao, $Y$ Zhu and $X$ Xue. Effects of berries consumption on cardiovascular risk factors: a meta-analysis with trial sequential analysis of randomized controlled trials, Sci. Rep., 2016; 6: 23625. https://doi.org/10.1038/srep23625

54. Williamson $\mathrm{G}$. The role of polyphenols in modern nutrition. Nutr. Bull., 2017; 42(3): 226-235. https:// doi.org/10.1111/nbu.12278

55. Gomaz JG. Potential Role of Polyphenols in the Prevention of Cardiovascular Diseases: Molecular Bases. Curr Med Chem, 2016; 23(2): 115-28. https:// doi.org/10.2174/0929867323666151127201732

56. Mendonca RD et al. Total polyphenol intake, polyphenol subtypes and incidence of cardiovascular disease: The SUN cohort study. Nutr Metab Cardiovasc Dis, 2019; 29(1): 69-78. https://doi.org/10.1016/j. numecd.2018.09.012

57. Murillo AG. The Relevance of Dietary Polyphenols in Cardiovascular Protection. Curr Pharm Des, 2017; 23(17): 2444-2452. https://doi.org/10.2174/1381612 823666170329144307

58. MA Kelm, JC Johnson, RJ Robbins, JF Hammerstone and HH Schmitz. High-performance liquid chromatography separation and purification of cacao (Theobroma cacao L.) procyanidins according to degree of polymerization using a diol stationary phase, $J$. Agric. Food Chem.,2006; 54: 1571-1576. https://doi. org/10.1021/jf0525941

59. SA Lazarus, JF Hammerstone, GE Adamson and HH Schmitz. High-performance liquid chromatography/ mass spectrometry analysis of proanthocyanidins in food and beverages, Methods Enzymol., 2001; 335: 4657. https://doi.org/10.1016/S0076-6879(01)35230-8

60. L Gu, MA Kelm, JF Hammerstone, G Beecher, J Holden, D Haytowitz and RL. Prior, Screening of foods containing proanthocyanidins and their structural characterization using LC-MS/MS and thiolytic degradation, J. Agric. Food Chem, 2003, 51, 7513-7521. https://doi.org/10.1021/jf034815d

61. ML McCullough, JJ Peterson, R Patel, PF Jacques, R Shah and JT Dwyer. Flavonoid intake and cardiovascular disease mortality in a prospective cohort of US adults, Am. J. Clin. Nutr., 2012; 95: 454-464. https://doi. org/10.3945/ajcn.111.016634

62. A Cassidy. Berry anthocyanin intake and cardiovascular health, Mol. Aspects Med., 2018; 61: 76-82. https:// doi.org/10.1016/j.mam.2017.05.002

63. A Cassidy, KJ Mukamal, L Liu, M Franz, AH Eliassen and EB Rimm. High anthocyanin intake is associated with a reduced risk of myocardial infarction in young and middle-aged women, Circulation, 2013; 127: 188-196. https://doi.org/10.1161/ CIRCULATIONAHA.112.122408

64. A Cassidy, M Bertoia, S Chiuve, A Flint, J Forman and EB Rimm. Habitual intake of anthocyanins and flavanones and risk of cardiovascular disease in men, Am. J. Clin. Nutr, 2016; 104: 587-594. https://doi.org/10.3945/ ajcn.116.133132

65. J Tome-Carneiro, M Larrosa, A Gonzalez-Sarrias, FA Tomas-Barberan, MT Garcia-Conesa and JC Espin. 
Resveratrol and clinical trials: the crossroad from in vitro studies to human evidence, Curr. Pharm. Des., 2013; 19: 6064-6093. https://doi.org/10.2174/1381 6128113199990407

66. M Gertz, GT Nguyen, F Fischer, B Suenkel, C Schlicker, B Franzel, J Tomaschewski, F Aladini, C Becker, D Wolters and C Steegborn. A molecular mechanism for direct sirtuin activation by resveratrol, PLOS ONE, 2012; 7: e49761. https://doi.org/10.1371/journal. pone.0049761

67. MS Bonkowski and DA Sinclair. Slowing ageing by design: the rise of $\mathrm{NAD}(+)$ and sirtuin-activating compounds, Nat. Rev. Mol. Cell Biol., 2016; 17: 679690. https://doi.org/10.1038/nrm.2016.93

68. NP Bondonno, CP Bondonno, LC Blekkenhorst, MJ Considine, G Maghzal, R Stocker, RJ Woodman, NC Ward, JM Hodgson and KD Croft. Flavonoid-rich apple improves endothelial function in individuals at risk for cardiovascular disease: a randomized controlled clinical trial, Mol. Nutr. Food Res., 2018; 62(3). https:// doi.org/10.1002/mnfr.201700674

69. WM Loke, JM Hodgson, JM Proudfoot, AJ McKinley, IB Puddey and KD Croft. Pure dietary flavonoids quercetin and (-)-epicatechin augment nitric oxide products and reduce endothelin-1 acutely in healthy men, Am. J. Clin. Nutr., 2008, 88: 1018-1025. https:// doi.org/10.1093/ajcn/88.4.1018

70. Danaei G, Finucane MM, Lu Y, Singh GM, Cowan MJ, Paciorek CJ \& et al. National, regional, and global trends in fasting plasma glucose and diabetes prevalence since 1980: systematic analysis of health examination surveys and epidemiological studies with 370 country-years and 2.7 million participants. Lancet, 2011; 378: 31-40. https://doi.org/10.1016/ S0140-6736(11)60679-X

71. Global status report on Diabetes diseases. Geneva, World Health Organization, 30 October 2018.

72. Xiao JB, Ni XL, Kai GY, Chen XQ. Advance in dietary polyphenols as aldose reductases inhibitors: Structureactivity relationship aspect. Crit. Rev. Food Sci. Nutr., 2015; 55: 16-31. https://doi.org/10.1080/10408398. 2011.584252

73. Stefek M. Natural flavonoids as potential multifunctional agents in prevention of diabetic cataract. Interdiscip. Toxicol, 2011; 4: 69-77. https://doi.org/10.2478/ v10102-011-0013-y

74. Dembinska-Kiec A, Mykkanen O, Kiec-Wilk B, Mykkanen H. Antioxidant phytochemicals against type 2 diabetes. Br. J. Nutr., 2008; 99: ES109- ES117. https:// doi.org/10.1017/S000711450896579X

75. Xiao JB, Hogger P. Dietary polyphenols and type 2 diabetes: current insights and future perspectives. Curr. Med. Chem., 2015; 22(1): 23-38. https://doi.org /10.2174/0929867321666140706130807

76. B Uttara, AV Singh, P Zamboni and RT Mahajan. "Oxidative stress and neurodegenerative diseases: a review of upstream and downstream antioxidant therapeutic options," Current Neuro pharmacology, 2009; 7(1): 65-74. https://doi. org/10.2174/157015909787602823

77. DA Butterfield and D Boyd-Kimball. "Amyloid $\beta$-peptide (1- 42) contributes to the oxidative stress and neuro degeneration found in Alzheimer disease brain," Brain Pathology, 2004; 14(4): 426-432. https://doi. org/10.1111/j.1750-3639.2004.tb00087.x

78. Patterson C. World Alzheimer Report, The state of the art of dementia research: New frontiers. London: Alzheimer's disease International, 2018.

79. FP Joseph, C Darrell Jennings, JK Richard et al. "Association of HFE mutations with neuro degeneration and oxidative stress in Alzheimer's disease and correlation with APOE," American Journal of Medical Genetics, 2003; 119: 48-53. https://doi.org/10.1002/ ajmg.b.10069

80. TD Bird. "Genetic aspects of Alzheimer disease," Genetics in Medicine, 2008; 10(4): 231-239. https:// doi.org/10.1097/GIM.0b013e31816b64dc

81. EH Verbon, JA Post and J Boonstra. "The influence of reactive oxygen species on cell cycle progression inmammalian cells," Gene., 2012; 511(1): 1-6. https:// doi.org/10.1016/j.gene.2012.08.038

82. Y Son, S Kim, H-T Chung and H-O Pae. "Reactive oxygen species in the activation of MAP kinases," Methods in Enzymology, 2013; 528: 27-48. https:// doi.org/10.1016/B978-0-12-405881-1.00002-1

83. GA Knock and JPT Ward. "Redox regulation of protein kinases as a modulator of vascular function," Antioxidants and Redox Signaling, 2011; 15(6): 15311547. https://doi.org/10.1089/ars.2010.3614

84. M Lo Conte and KS Carroll. "The redox biochemistry of protein sulfenylation and sulfinylation," The Journal of Biological Chemistry, 2013; 288(37): 26480-26488. https://doi.org/10.1074/jbc.R113.467738

85. X Chen, C Guo and J Kong. "Oxidative stress in neurodegenerative diseases," Neural Regeneration Research, 2012; 7(5): 376-385.

86. ZXie, M Wei, TE Morgan et al. "Peroxynitrite mediates neurotoxicity of amyloid beta-peptide1-42- and lipopolysaccharide- activated microglia," The Journal of Neuroscience, 2002; 22(9): 3484-3492. https://doi. org/10.1523/JNEUROSCI.22-09-03484.2002

87. K Van Dyke. "The possible role of peroxynitrite in Alzheimer's disease: a simple hypothesis that could be tested more thoroughly," Medical Hypotheses, 1997; 48(5): 375-380. https://doi.org/10.1016/S03069877(97)90031-1

88. RE Hartman, A Shah, AM Fagan et al. "Pomegranate juice decreases amyloid load and improves behavior in amouse model of Alzheimer's disease," Neurobiology of Disease, 2006; 24(3): 506-515. https://doi. org/10.1016/j.nbd.2006.08.006

89. S Subash, MM Essa, A Al-Asmi, S Al-Adawi, R Vaishnav, and GJ Guillemin. "Effect of dietary supplementation of dates in Alzheimer's disease APPsw/2576 transgenic mice on oxidative stress and antioxidant status," Nutritional Neuroscience, 2015; 18(6): 281-288. https://doi.org/10.1179/1476830514Y.0000000134

90. B Muthaiyah, MM Essa, V Chauhan and A Chauhan. "Protective effects of walnut extract against amyloid beta peptide-induced cell death and oxidative stress in PC12 cells," Neurochemical Research, 2011; 36(11): 2096-2103. https://doi.org/10.1007/s11064-0110533-z

91. Dental Health Foundation, Ireland, 2019 reports. World 
Health Organization. Oral health Information Sheet 24 September 2018 Available at: who.int/oral_health/ publications/factsheet/en/.

92. Luczaj W and Skrzydlewska E. Antioxidative properties of black tea. Prev. Med., 2000; 40: 910-918. https:// doi.org/10.1016/j.ypmed.2004.10.014

93. Milgrom P, Riedy CA, Weinstein P, Tanner AC, Manibusan $L$ and Bruss J. Dental caries and its relationship to bacterial infection, hypoplasia, diet, and oral hygiene in 6- to 36-month-old children. Community Dent.Oral Epidemiol., 2000; 28: 295-306. https://doi.org/10.1034/j.1600-0528.2000.280408.x

94. Manitto P. Biosynthesis of Natural Products. Ellis Horwood Ltd.; Chichester and New York, UK: 1981.

95. Matsumoto $M$, Minami T, Sasaki $H$, Sobue $S$, Hamada S, Ooshima T. Inhibitory effects of oolong tea extract on caries-inducing properties of mutans streptococci. Caries Res., 1999; 33: 441-445. https:// doi.org/10.1159/000016549

96. Rukayadi Y, Hwang JK. In vitro activity of xanthorrhizol against Streptococcus mutans biofilms. Lett. Appl. Microbiol., 2006; 42: 400-404. https://doi. org/10.1111/j.1472-765X.2006.01876.x

97. Saito N. Anti-caries effects of polyphenol compound from Camellia sinensis. Nichidai Koko Kagaku., 1990; 16: $154-163$

98. Osawa K, Yasuda H, Maruyama T, Morita H, Takeya $\mathrm{K}$, Itokawa $\mathrm{H}$. Isoflavanones from the heartwood of Swartziapolyphylla and their antibacterial activity against cariogenic bacteria. Chem. Pharm. Bull., 1992; 40: 2970-2974. https://doi.org/10.1248/cpb.40.2970

99. Osbourn AE. Preformed antimicrobial compounds and plant defense against fungal attack. Plant Cell, 1996; 10: 1821-1831. https://doi.org/10.1105/tpc.8.10.1821

100. Sakagami H, Oi T, Satoh K. Prevention of oral diseases by polyphenols. In vivo., 1999; 13: 155-171.

101. Sampaio FC, Pereira MS, Dias CS, Costa VC, Conde NC, Buzalaf MA. In vitro antimicrobial activity of Caesalpiniaferrea Martius fruits against oral pathogens. J. Ethnopharmacol., 2009; 15: 289-294. https://doi.org/10.1016/j.jep.2009.04.034

102. Sang S, Lambert JD, Tian S, Hong J, Hou Z, Ryu JH, Stark RE, Rosen RT, Huang MT, Yang CS, Ho CT. Enzymatic synthesis of tea theaflavin derivatives and their antiinflammatory and cytotoxic activities. Bioorg. Med. Chem., 2004; 12: 459-467. https://doi.org/10.1016/j. bmc.2003.10.024
103. Sato M, Fujiwara S, Tsuchiya H, Fujii T, Tinuma M, Tosa H, Ohkawa Y. Flavones with antibacterial activity against cariogenic bacteria. J. Ethnopharmacol; 1996; 54: 171-176. https://doi.org/10.1016/S03788741(96)01464-X

104. Yamammoto H, Ogawa T. Antimicrobial activity of Perilla seed polyphenols against oral pathogenic bacteria. Biosci. Biotechnol. Biochem., 2002; 66: 921924. https://doi.org/10.1271/bbb.66.921

105. Sato M, Tanaka H, Fujiwara S, Hirata M, Yamaguchi R, Etoh H, Tokuda C. Antibacterial property of isoflavonoids isolated from Erythrinavariegata against cariogenic oral bacteria. Phytomedicine, 2003; 10: 427-433. https://doi.org/10.1078/0944-7113-00225

106. Linke HA, LeGeros RZ. Black tea extract and dental caries formation in hamsters. Int. J. Food Sci. Nutr. 2003; 54: 8995. https://doi.org/10.1080/096374803/000062029

107. Bouarab-Chibane L, Degraeve P, Ferhout $H$, Bouajila $\mathrm{J}$ and Oulahal N. Plant antimicrobial polyphenols as potential natural food preservatives. J. Sci. Food Agric., 2019; 99: 1457-1474. https://doi.org/10.1002/ jsfa.9357

108. Kocevar Glavac N and Lunder M. Preservative efficacy of selected antimicrobials of natural origin in a cosmetic emulsion. Int. J. Cosmetic Sci., 2018; 40: 276-284. https://doi.org/10.1111/ics.12461

109. Sikkema J, de Bont JA and Poolman B. Mechanisms of membrane toxicity of hydrocarbons. Microbiol. Rev., 1995; 59: 201-222. https://doi.org/10.1128/ MMBR.59.2.201-222.1995

110. Ikigai $\mathrm{H}$, Nakae T, Hara $\mathrm{Y}$ and Shimamura T. Bactericidal catechins damage the lipid bilayer. Biochim. Biophys. Acta, 1993; 1147: 132-136. https://doi. org/10.1016/0005-2736(93)90323-R

111. Stapleton PD, Shah S and Hamilton-Miller JMT. AntiStaphylococcus aureus activity and oxacillin resistance modulating capacity of 3- O-acylcatechins. Int. J. Antimicrob. Agents, 2004; 24: 374-380. https://doi. org/10.1016/j.ijantimicag.2004.03.024

112. Taguri T, Tanaka T and Kouno I. Antibacterial spectrum of plant polyphenols and extracts depending upon hydroxyphenyl structure. Biol. Pharm. Bull., 2006; 29: 2226-2235. https://doi.org/10.1248/bpb.29.2226

113. Cushnie TT and Lamb AJ. Recent advances in understanding the antibacterial properties of flavonoids. Int. J. Antimicrob. Agents, 2011; 38: 99-107. https://doi.org/10.1016/j.ijantimicag.2011.02.014 